\title{
ENTRE AS
}

TRANSFORMAÇÕES

NOS MODOS DE

MORAR E AS

VICISSITUDES

DA HABITAÇÃO

ENQUANTO

PATRIMÔNIO

IMOBILIÁRIO:

COMO PRESERVAR O VALOR CULTURAL DA HABITAÇÃO?

JOSÉ EDUARDO DE ASSIS LEFÈVRE UNIVERSIDADE DE SÃO PAULO, SÃO PAULO, SÃO PAULO, BRASIL Arquiteto com graduação, mestrado e doutorado pela Faculdade de Arquitetura e Urbanismo da Universidade de São Paulo (FAU-USP). Professor doutor do Departamento de História da FAU-USP. Foi presidente do Conpresp (2005-2013) e do Condephaat (2016).

E-mail: jealef@usp.br.

DOI

http://dx.doi.org/10.11606/issn.1980-4466.v0iesp22p233-254 


\section{ENTRE AS TRANSFORMAÇÕES NOS MODOS DE MORAR E AS VICISSITUDES DA HABITAÇÃO ENQUANTO PATRIMÔNIO IMOBILIÁRIO: COMO PRESERVAR O VALOR CULTURAL DA HABITAÇÃO? \\ JOSÉ EDUARDO DE ASSIS LEFÈVRE}

\section{RESUMO}

A preservação de construções residenciais constitui-se uma das questões mais complexas para os órgãos de preservação. Seja pela transitoriedade das formas de morar e hábitos de vida, seja pelo muito alto ou pelo muito baixo valor econômico-financeiro que apresentam. Quando se trata de edifícios institucionais é mais factível estabelecer bases e identificar interesses na sua preservação. Quando se trata de edifícios de propriedade coletiva, condominial, e também um edifício de notória qualidade arquitetônica, a preservação pode se viabilizar como uma forma de reconhecer e consolidar um patrimônio reconhecido pelos seus moradores e proprietários. É com as moradias unifamiliares que as dificuldades de preservação se avolumam. Em particular, se há intenção de manter o uso residencial. É fundamental que proprietários e responsáveis por bens de interesse cultural estejam convencidos e tenham interesse na sua valorização através da preservação.

\section{PALAVRAS-CHAVE}

Edifícios residenciais. Patrimônio ambiental urbano. Mercado imobiliário. 


\title{
THE TRANSFORMATIONS IN THE WAY OF LIVING AND HOUSING NECESSITIES AS REAL ESTATE HERITAGE: HOW TO PRESERVE THE CULTURAL VALUE OF HOUSING? \\ JOSÉ EDUARDO DE ASSIS LEFÈVRE
}

\begin{abstract}
Preserving residential buildings is one of the most complex issues preservation agencies face. Be it for the transience in the ways of living and life habits, be it for their too-high or too-low economic and financial value. It is much more feasible to establish foundations and identify interests to conserve institutional buildings. When dealing with collectively-owned buildings, condominiums, and buildings with notorious architectural quality, conservation might present itself as a way to acknowledge and consolidate heritage already acknowledge by the building's residents and owners. The conservation difficulties are much greater when dealing with single-family housing buildings. Especially when there is an intent to keep the building's residential use. It is fundamental that owners and managers of cultural interest assets are convinced and interested in the buildings' appreciation through conservation.
\end{abstract}

KEYWORDS

Residential building. Urban environment heritage. Real estate market. 


\section{INTRODUÇÃO}

A preservação de construções residenciais constitui-se uma das questões mais complexas para os órgãos de preservação. Seja pela transitoriedade das formas de morar e hábitos de vida, seja pelo muito grande ou pelo muito pequeno valor econômico-financeiro que apresentam. Quando se trata de edifícios institucionais é factível estabelecer bases e identificar interesses na sua preservação. Quando se trata de edifícios de propriedade coletiva, condominial, se também se trata de um edifício de notória qualidade arquitetônica, a preservação pode se viabilizar como forma de consolidar um patrimônio reconhecido pelos seus moradores e proprietários.

É com as moradias unifamiliares que as dificuldades de preservação se avolumam, devido aos dilemas já colocados no título desta apresentação. Em particular, se há a intenção de manter o uso residencial, essencial para preservar o seu valor cultural. Conciliar preservação com valorização é uma das metas que me propus a perseguir ao assumir a presidência do Conselho de Defesa do Patrimônio Histórico Arqueológico, Artístico e Turístico (Condephaat). Essa meta é essencial, em meu ver, para constituir uma política pública cultural. É fundamental que proprietários e responsáveis por bens de interesse cultural estejam convencidos e tenham interesse na sua valorização pela preservação. A primeira dificuldade a enfrentar é caracterizar, para cada tipologia de habitação, quais valores 
culturais se apresentam como significativos. A segunda, identificar para quem, para quais grupos esses valores são significativos, e relacionar esta valorização com os detentores de sua propriedade ou, em última análise, com os responsáveis pela sua manutenção.

Ao propor, nesse contexto, o estabelecimento de uma tipologia de edificações residenciais, reconhecemos a necessidade de estabelecer especificidades e afinidades que facilitem uma abordagem mais definida para cada caso. Nessa perspectiva, a tipologia das construções residenciais pode ser estabelecida a partir de algumas características: unifamiliar ou plurifamiliar, integrante ou não de um conjunto edificado e/ou de um conjunto de edificações, de propriedade particular ou pública, em uso ou abandonada, com uso residencial mantido ou não, de alto, médio ou baixo valor econômico-financeiro, com reconhecido valor arquitetônico específico da obra ou representativo de uma determinada forma usual de construções, com ou sem valor histórico de natureza não arquitetônica, com ou sem percepção coletiva de valor patrimonial em um dado momento.

Como se pode deduzir, é muito diversificada a gama de diferenças e nuances das construções residenciais, com a consequente diversificada gama de abordagens e problemas para a sua conservação patrimonial. Como a habitação é o espaço privado individual ou familiar por excelência, como estabelecer parâmetros para a sua valorização patrimonial cultural, que é uma instância coletiva e compartilhada? O reconhecimento do valor do projeto arquitetônico é um elemento que transcende as fronteiras estritamente privadas, o que pode causar eventuais desconfortos aos proprietários de imóveis. Mas a perda, por demolição ou desfiguração de imóveis de importância fundamental para a história da arquitetura constitui uma perda cultural imensa, sentida por profissionais, estudantes, historiadores e público conhecedor. Especialmente no caso de residências unifamiliares esse conflito é mais grave, pois se trata de uma interlocução entre o proprietário ou proprietários de um bem privado e uma comunidade que reconhece valor naquele bem, sem, contudo, ter ingerência direta na sua preservação. No caso de edifícios multifamiliares, como prédios de apartamentos, um conjunto de proprietários encontra-se irmanado em uma relação de identidade que pode proporcionar retorno econômico-financeiro de demanda, além de apresentar uma dificuldade maior em introduzir modificações autônomas nas construções. 
O fato de um imóvel residencial apresentar valor econômico-financeiro alto ou baixo leva a diferentes problemas. $\mathrm{O}$ valor baixo está associado a um quadro de dificuldades de investimento na manutenção básica da construção: de onde vêm os recursos para tanto? O valor alto está associado a outro espectro de dificuldades: como resolver os problemas sucessórios da propriedade, causa da maior porcentagem de demolições de residências unifamiliares? No caso de apartamentos, essa questão não é tão crucial, ao menos no exterior das edificações. Não há dúvidas de que a viabilidade de preservação de residências unifamiliares de qualidade arquitetônica reconhecida está associada à existência de uma demanda por esse tipo de moradias. Por outro lado, muitas residências paradigmáticas projetadas por arquitetos modernos, em especial os projetados para sua própria moradia, se afastam dos padrões usuais de mercado, tornando mais difícil a sua preservação com o uso residencial. Um caso exemplar é a residência projetada pelo arquiteto Hans Broos, um magnífico projeto, combinado com jardim projetado por Roberto Burle Marx. Até agora, o que se sabe é que não foi encontrada uma solução para a sua preservação. Mas a preservação da habitação como patrimônio cultural depende essencialmente da identificação de quais são os valores a ela associados e reconhecidos e também qual é a amplitude desse reconhecimento. Diversos fatores podem se apresentar como elementos de valor: aspectos históricos, aspectos de emoção estética, de significados, de identidade e de pertencimento. O reconhecimento do valor da habitação como patrimônio cultural não é uma manifestação privativa dos arquitetos ou historiadores da arquitetura, embora sua contribuição seja essencial.

Grande parte do valor atribuído à habitação como patrimônio está ligada às associações que os exemplares em análise proporcionam. A associação a eventos e experiências públicas, comunitárias ou individuais pode definir o valor representado pela habitação. O caso do famoso conjunto Pruitt-Igoe em Saint Louis, Estados Unidos, é paradigmático quanto à diversidade de significados que uma mesma obra pode assumir. Uma residência reconhecida como excepcional pelos arquitetos e historiadores da arquitetura pode ter essa valorização compartilhada apenas por um pequeno público externo à comunidade de arquitetos e historiadores. Se a obra não está em evidência no ambiente urbano e está apenas na memória de umas tantas pessoas, como alcançar o grau de valorização que justifique a sua preservação? 


\section{RESIDÊNCIAS UNIFAMILIARES DE BAIXO VALOR ECONÔMICO E DE INTERESSE PARA PRESERVAÇÃO}

Vamos enfocar aqui dois conjuntos de residências unifamiliares que apresentam interesse para preservação e baixo valor econômico-financeiro por unidade. O primeiro é um conjunto de imóveis localizados no bairro da Lapa de Baixo, em São Paulo e o segundo um conjunto de casas de madeira localizado nos bairros do Embaré e Jabaquara, em Santos-SP.

Entre os imóveis indicados pela Câmara Municipal de São Paulo para integrar as ZEPEC, Zonas Especiais de Preservação Cultural, criadas pela Lei n. 13.885 de 25 de agosto de 2004, que aprovou o Plano Diretor Estratégico do Município de São Paulo estava um conjunto de imóveis de características correntes na cidade inteira no início do século XX, identificadas pela tipologia 'casas de porão alto com entrada lateral', estudadas por Nestor Goulart Reis Filho (REIS FILHO, 1970) e Carlos Alberto Cerqueira Lemos (LEMOS, 1976). Extremamente numeroso na cidade, esse tipo de edificação, principalmente de classe média baixa e de caráter popular, usualmente construído para locação, tem sido destruído ou descaracterizado em grande quantidade nos bairros em que ocorre a valorização imobiliária e a verticalização. Feito em alvenaria, com esquadrias de janelas com o vidro na parte externa, com uma decoração eclética artesanal, executado por mestres de obras majoritariamente italianos e portugueses, constitui atualmente o remanescente de uma forma de morar que caracterizava a fisionomia da cidade, da Lapa à Penha, de Santana a Santo Amaro. Tratando-se de uma arquitetura frágil, é facilmente descaracterizada pela alteração das esquadrias, pela inserção de materiais de revestimento de parede de fabricação atual, pela introdução de aberturas para uso comercial. A sua preservação íntegra, hoje, é a exceção.

Estando incluídas na relação de imóveis para preservação como ZEPEC, diversas casas foram objeto da Resolução 26/CONPRESP/2004 que definiu sua Abertura de Processo de Tombamento. A partir da análise feita pelo Departamento de Patrimônio Histórico (DPH), o Conselho Municipal de Preservação do Patrimônio Histórico, Cultural e Ambiental da Cidade de São Paulo (Conpresp) decidiu manter, em 2009, o status de Abertura de Processo de Tombamento, em conjunto com outros imóveis, para estudar formas e procedimentos que viabilizassem a sua preservação, 
sem a aplicação do Tombamento Definitivo, considerado inadequado para o seu caso.A inadequação levada em consideração se deve à observação da evidência de que os custos de preservação e restauro desses imóveis certamente ultrapassariam a capacidade de investimento de seus proprietários e tampouco seriam ressarcidos pela exploração econômica através da locação. E também pela evidência de que a expropriação desses imóveis pelo poder público poderia preservar a sua materialidade, mas não o seu valor cultural como habitação.

O segundo caso que será enfocado é constituído por um conjunto de casas construídas em madeira e localizadas na cidade de Santos, em São Paulo. Trata-se também de uma forma de moradia extremamente corriqueira em Santos no final do século XIX e início do XX, e que está em

FIGURA 1

Casa à Rua Félix

Guilhem, 1092,

Lapa de Baixo, São Paulo-SP. Integrante

da lista de bens em

Abertura de Processo

de Tombamento pelo CONPRESP

Resolução $\mathrm{n}$.

$26 / 2004$. Foto do

autor. Agosto de 2008.

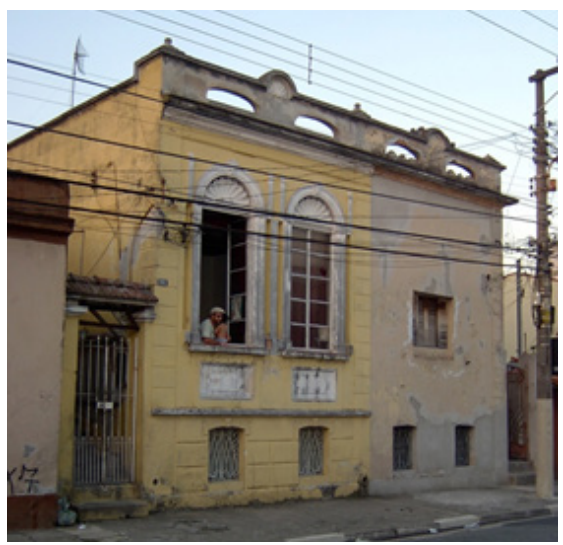

FIGURA 2

Casa à Rua Antonio

Fidélis, 55, Lapa de

Baixo, São Paulo-SP.

Integrante da lista

de bens em Abertura

de Processo de

Tombamento

pelo CONPRESP,

Resolução $\mathrm{n}$.

26/2004. Foto do

autor. Agosto de

2008.

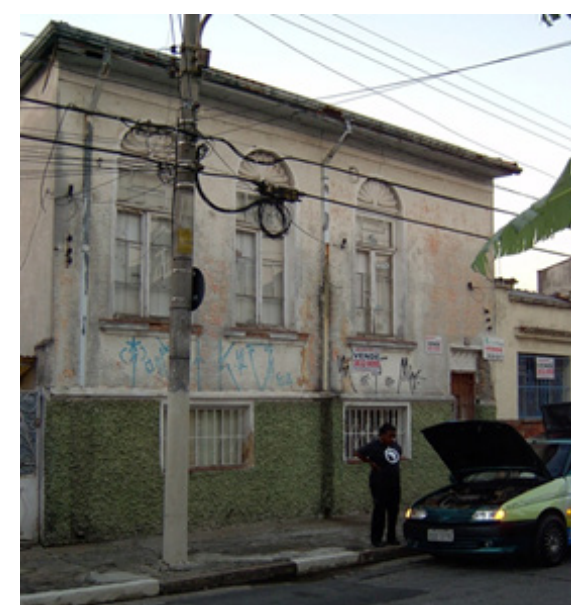


acelerado desaparecimento. Essa forma de moradia foi objeto de estudos em 1990, pelo arquiteto Vitor Campos (CAMPOS, 1990), do Condephaat, em trabalho para o Curso de Pós-graduação da FAU-USP entre 1991, e em 1998 pelo arquiteto Gino Caldatto Barbosa (CALDATTO BARBOSA, 1998) em seu mestrado, bem como em um interessante trabalho de conclusão de curso desenvolvido pelo arquiteto Roberto Ferreira da Silva (DA SILVA, 2008) enquanto aluno de graduação da Universidade Santa Cecília. No ano de 2000 a Promotoria de Justiça Cível de Santos, do Ministério Público do Estado de São Paulo, encaminhou ao Condephaat pedido de informações a respeito da existência de medidas de proteção para as casas de madeira mencionadas em notícia publicada no jornal A Tribuna de Santos, na qual havia informações a respeito dos estudos desenvolvidos pelo arquiteto Gino Caldatto. Essa solicitação motivou a abertura do procedimento conhecido como Guichê, com o número 00751/2000, para instruir eventual decisão de tombamento daquelas construções, a ser tomada pelo Conselho. Em dezembro de 2014 (CONDEPHAAT, 2014) o Conselho decidiu abrir o Processo de Tombamento de um conjunto de 67 desses chalés. Posteriormente, em março de 2015, a lista de imóveis foi reduzida a um conjunto de 56 chalés, após retificação feita a partir de informações cadastrais da Prefeitura Municipal de Santos.

A decisão do Condephaat gerou manifestações contrárias de proprietários desses imóveis, alguns destes residentes nos chalés, bem como de alguns políticos, vereadores e ainda de um deputado estadual. O Conselho ainda não deliberou a respeito do tombamento definitivo dessas casas. Em ambos os conjuntos pode-se prever que o instituto do tombamento pode impedir a demolição das casas, mas não garante a sua preservação material nem a preservação do seu valor cultural como habitação. Para tanto, acreditamos que é necessário mudar o foco das medidas voltadas para a preservação, da pretendida proteção para a necessária promoção da preservação. Ao focarmos somente na proteção, apenas nos preocuparemos com medidas restritivas, negativas, cujos resultados tendem a ser sempre parciais. Ao pensarmos na promoção, estaremos voltados para aspectos positivos, de valorização, de encontrarmos objetivos comuns, de superação de conflitos. A preservação compulsória da materialidade das casas não garante a preservação de seu uso como habitação. Ao lidar com construções 
simples e construídas em uma época em que o desenvolvimento tecnológico era de outro nível, muito diferente do disponível hoje, não se pode pretender que os moradores continuem a viver como se vivia há cem anos. Ou seja, é necessário identificar os valores a serem preservados e possibilitar a adoção de providências que compatibilizem as necessidades de hoje com esses valores.

A promoção da preservação deve levar em conta a necessidade constante e perpétua de manutenção dos bens imóveis, ou seja, é necessário

FIGURA 3

Casa de madeira na Rua Torres Homem, Santos-SP. Foto de Amanda Caporrino, GEI-UPPH

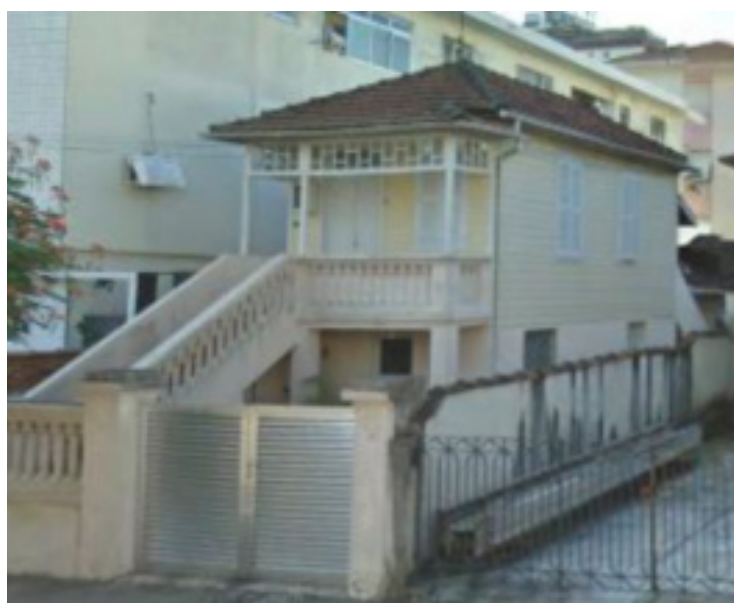

FIGURA 4

Casa de madeira na Rua Teodoro Sampaio, Santos-SP

Foto de Amanda Caporrino, GEIUPPH.




que a promoção seja sustentada enquanto o imóvel esteja em bom estado de conservação, e cesse se houver a sua degradação. A transferência de potencial construtivo representa, sob esse aspecto, uma armadilha, pois sendo um recurso não renovável, ao se esgotar a sua utilização não restarão alternativas para levantamento de recursos.

Antes de concluir este tópico, mencionarei um caso interessante e excepcional exatamente pela sua singularidade, que é o de uma casa

FIGURA 5

Casa em madeira à Rua do Bosque esquina com Rua da Várzea, Barra Funda, São Paulo-SP. Foto do autor. 2014

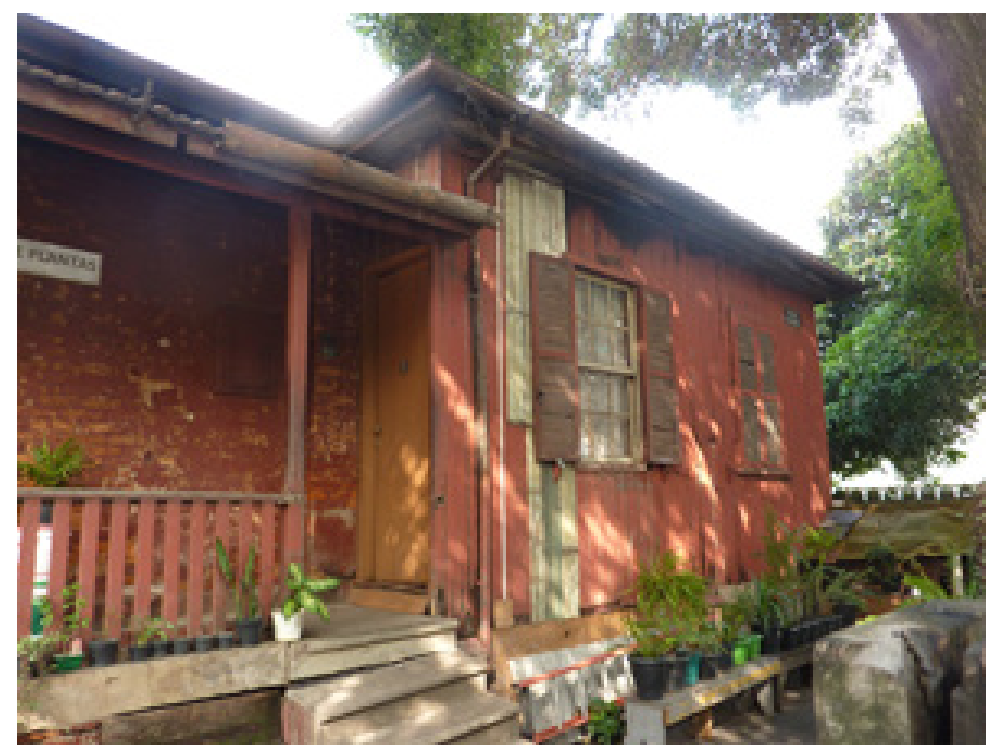

FIGURA 6

Detalhe da Folha 36 do Levantamento Aerofotogramétrico

SARA Brasil, de

1930, mostrando a localização da casa em madeira da Rua do Bosque.Biblioteca FAU-USP.

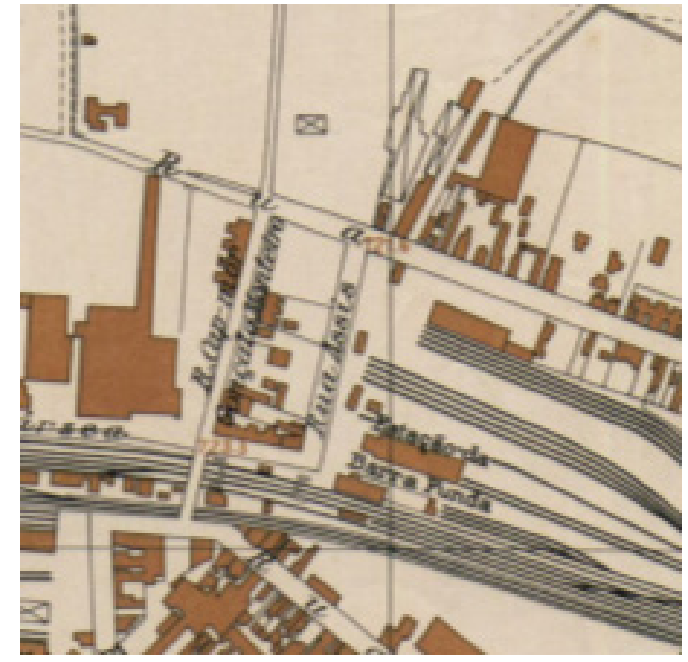


em madeira existente ainda em São Paulo, que certamente integraria um conjunto com outras unidades, hoje desaparecidas ou não identificadas. Trata-se de uma pequena casa localizada à Rua do Bosque, em frente à Rua James Holland e junto à esquina da Rua da Várzea. Na Figura 6, detalhe da Folha 36 do levantamento aerofotogramétrico SARA Brasil, de 1930, foi identificada a presença dessa pequena casa. Naquela ocasião o trecho em cotovelo da Rua da Várzea apresentava o nome Rua Assis. A identificação da Rua James Holland aparece fora do trecho destacado. Pelo seu aspecto, cor e localização, pode-se supor que faria parte do conjunto de construções ferroviárias ligadas a ou de propriedade da São Paulo Railway, composto

por galpões ainda existentes na mesma quadra. Essa construção sobreviveu pelo seu parco significado econômico e/ou dificuldade de comercialização. Ela deveria ser tombada? Quase certamente que não, pois não dispomos de mecanismos para proporcionar a devida preservação. Mas a sua existência muito apropriadamente deveria ser registrada e documentada, pela sua singularidade e como memória da diversidade de formas de moradia presentes na capital paulista.

\section{RESIDÊNCIAS UNIFAMILIARES DE VALOR ECONÔMICO ALTO E DE INTERESSE PARA PRESERVAÇÃO}

Mencionamos o caso da residência projetada e construída pelo arquiteto Hans Broos. Nascido na Áustria, em 1921, estudou arquitetura em Praga e concluiu o curso em Braunschweig, Alemanha, em 1947 (DAUFENBACH, 2010). Vindo para o Brasil em 1953, radicou-se em Blumenau e posteriormente em São Paulo. Desenvolveu uma carreira profissional muito bem sucedida e seu escritório elaborou um conjunto de obras expressivo e reconhecido pela qualidade, inserido no panorama da arquitetura brasileira moderna. Em 1971 projetou e iniciou a construção de uma casa para si no bairro do Morumbi, em São Paulo, em terreno com frente para duas ruas, conjugando nele a construção destinada a seu escritório. O paisagismo foi projetado por Roberto Burle Marx. Em 2008 o Conpresp, através da Resolução n. 09/2008, abriu o Processo de Tombamento (CONPRESP, 2008) dessa casa, solicitado por pessoas próximas ao arquiteto, que na ocasião já contava 87 anos de vida e, não tendo herdeiros diretos, manifestara a disposição de doar em testamento o imóvel para uma instituição pública voltada para 
o ensino de arquitetura. Submetida a proposta de doação à apreciação da FAU-USP, não foi aceita, por razões financeiras.

A abertura de processo de tombamento da Residência Hans Broos está ligada diretamente à qualidade de sua arquitetura e à integração das atividades de residência e trabalho e também à integração entre arquitetura, paisagismo e obras de artes plásticas aderentes, como os painéis móveis em relevo junto à lareira. A particularidade do programa da obra já indica a dificuldade de encontrar uma sucessão na propriedade que inclua a permanência do uso residencial. O mais provável seria a ocorrência de mudanças drásticas no uso e ambiente da casa. A destinação da obra para funções ligadas ao ensino e pesquisa de arquitetura poderia incluir um uso residencial temporário para convidados e sede de instalações ligadas à pesquisa em arquitetura, ou seja, algo próximo de uma casa-museu. Preservaria-se a materialidade da casa, mas não o uso original. Pelo exemplo da Vila Penteado, tombada e em uso pela Pós-Graduação da FAU-USP, pode-se aquilatar a distância com relação ao uso residencial e a dificuldade do poder público em manter o imóvel em perfeito estado de conservação.

\section{A PRESERVAÇÃO DE RESIDÊNCIAS E DO AMBIENTE RESIDENCIAL EM BAIRROS TOMBADOS}

Esta é uma questão difícil e espinhosa. A dinâmica urbana se traduz em

FIGURA 7

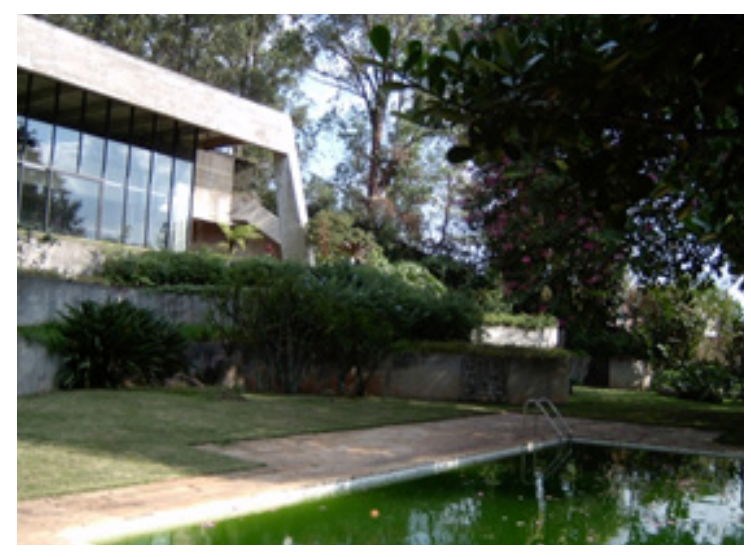


FIGURA 8

Residência Hans Broos. Vista interna.

Lareira e paine móvel em concreto. Foto do autor. 2007.

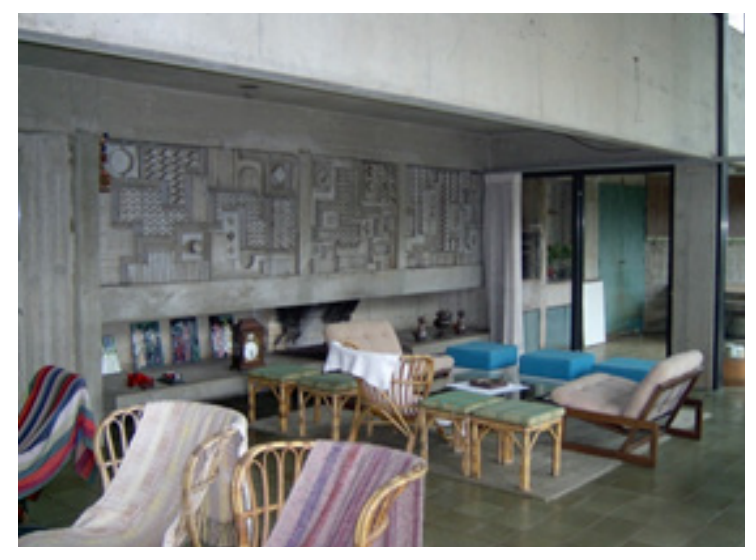

FIGURA 9

Residência Hans Broos. Vista externa com detalhe de iluminação zenital/ ventilação do escritório em primeiro plano. Foto do autor. 2007



FIGURA 10

Residência Hans Broos. Vista interna do escritório. Foto do autor. 2007

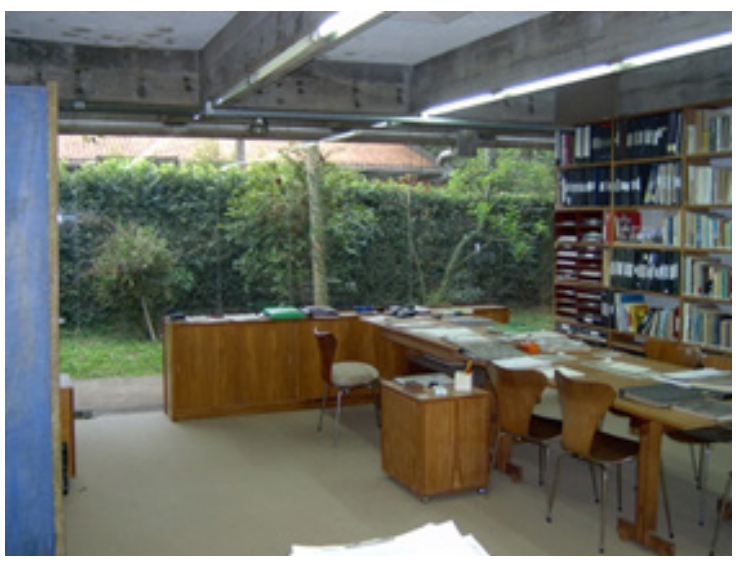


mudanças radicais nos ambientes urbanos, resultando em conflitos insuperáveis sem mudanças também grandes nas atitudes, nos comportamentos coletivos e nas práticas sociais. Numerosas áreas da cidade de São Paulo definidas pelo zoneamento como Zonas Estritamente Residenciais foram tombadas pelo Condephaat e Conpresp com vistas à manutenção de características como o traçado das ruas, a ocupação dos lotes e a arborização. O objetivo implícito do tombamento era a preservação de seu patrimônio ambiental. Porém, o ambiente é afetado por questões que extrapolam o âmbito dessa regulamentação e degradam o patrimônio ambiental. Em especial dois são os fatores mais perturbadores do ambiente: a presença $\mathrm{e}$ circulação de veículos e a segurança pública. Quanto a esses dois fatores, é quase impossível chegar a um consenso, pois o envolvimento emocional com os temas leva a posições extremas que resultam inoperantes e inaceitáveis: a circulação de veículos perturba o ambiente urbano? Sim. Mas como limitá-la? Proibindo a circulação imediatamente? Seria impraticável. Mas é necessário que a circulação, principalmente de veículos de transporte individual de quatro rodas, seja progressivamente restringido e que haja uma consciência coletiva a esse respeito. A questão da segurança pública é exclusivamente uma questão social ou uma questão de policiamento?

Também aqui as duas posturas extremas se revelam inoperantes. Não podemos esperar que os problemas sociais sejam totalmente resolvidos para depois tomar alguma iniciativa, muito menos imaginar que apenas o policiamento irá resolverá essa questão. Traremos aqui uma abordagem sobre como essas questões interferem diretamente na preservação do ambiente residencial em bairros tombados, mas evidentemente que interferem no ambiente de toda a cidade.

A Rua Venezuela, no Jardim América, foi uma rua tranquila até os anos 1960. Tornando-se progressivamente uma via de ligação viária de uso intenso por automóveis, seu ambiente foi altamente modificado. Do mesmo modo, até os anos 1970 o problema de segurança em São Paulo tinha contornos muito menos traumáticos do que atualmente. O resultado combinado desses dois fatores levou a uma alteração ambiental e comportamental de monta, com o alteamento de muros de fechamento e colocação de barreiras de arame farpado que tornaram a arquitetura residencial praticamente invisível, combinada com o aspecto urbano das ruas como 
muros e corredores de penitenciárias. Trazemos aqui a lembrança de duas casas de arquitetura moderna exponencial que hoje são invisíveis: uma casa projetada pelo arquiteto Rino Levi e outra projetada pelo arquiteto Victor Reif.

A residência projetada por Rino Levi à Rua Venezuela apresentava quase metade da área do lote como jardins integrados ao espaço público das

FIGURA 11

Residência à Rua Venezuela, projeto

de Rino Levi. Publicada em Rino Levi, 1974. Foto

Arquivo Rino Levi

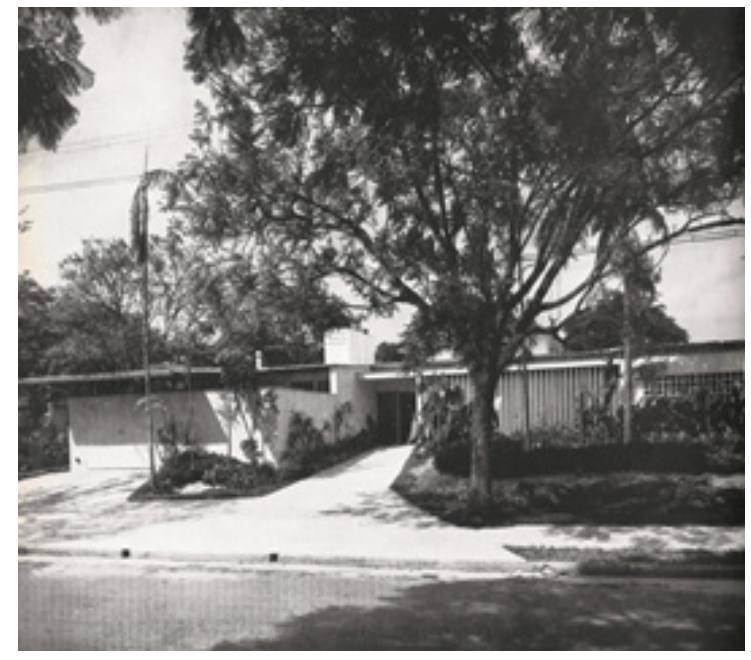

FIGURA 12

Planta da residência à Rua Venezuela, projeto de Rino Levi. (ANELLI, GUERRA KON, 2001)

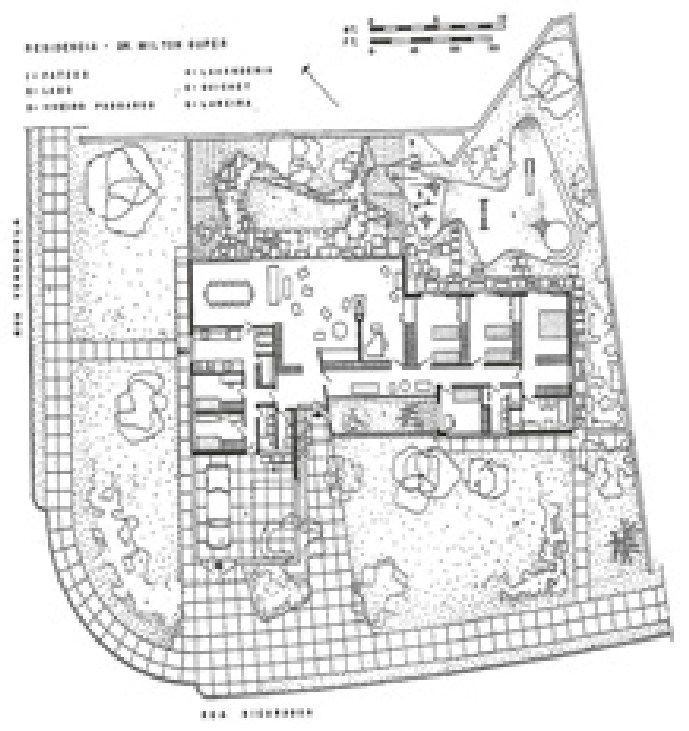


ruas. Os recuos obrigatórios estabelecidos pela Companhia City não eram cercados. A arquitetura residencial era, assim, participante e qualificadora do espaço público, postura intencional de muitos arquitetos em atuação nos anos 1950.

Um detalhe desse projeto de Rino Levi é revelador de um dos hábitos residenciais daquele momento, tratado pelo arquiteto de maneira inovadora: era costume, antes da difusão dos supermercados, que empórios e mercearias tivessem serviço de entrega de gêneros em domicílio por bicicletas com cestas. Neste projeto, além de colocar a cozinha em contato direto com a rua, o que não era de forma alguma usual, colocou um acesso direto da

FIGURA 13

Residência à Rua Venezuela, projeto de Rino Levi. Fachada de serviço. Ao centro o guichet da janela da cozinha. (MINDLIN, 1956) Foto: PC Scheier

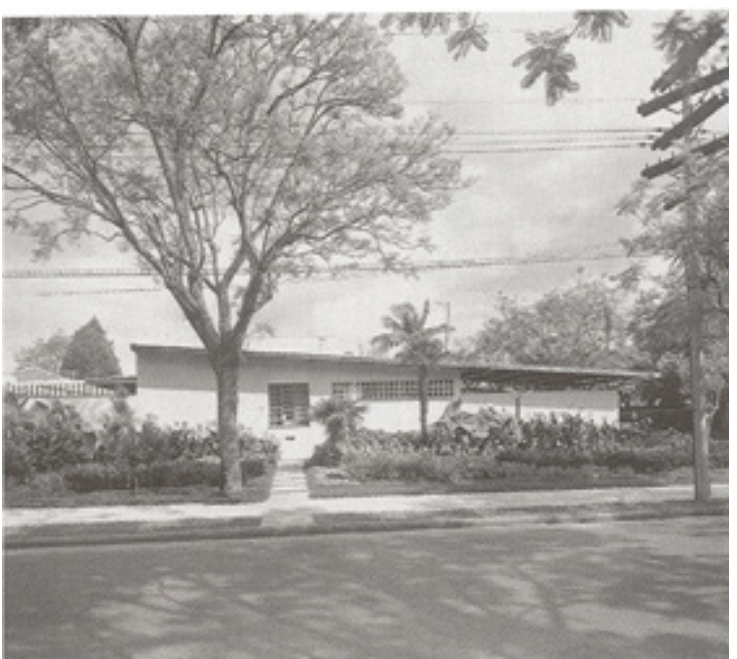

FIGURA 14

Residência à Rua Venezuela, projeto

de Victor Reif. (ACAYABA, 1986) Foto: José Moscardi.




calçada à janela da cozinha, indicada em planta como guichet, ou seja, uma abertura para receber a entrega da mercearia, o que eliminava a necessidade de o entregador tocar a campainha e a empregada ir ao portão. Hoje uma curiosidade, mas indicativa de hábitos de morar.

A residência projetada por Victor Reif à Rua Venezuela recebeu o prêmio Governador do Estado de São Paulo no $8^{\circ}$ Salão Paulista de Arte Moderna, em 1959. A casa era totalmente visível da rua, de vez que o fechamento no limite do terreno era feito com um gradil metálico baixo e vazado. Também neste caso a arquitetura residencial era protagonista do ambiente urbano, qualificando-o. Ambas as casas, importantes para o conhecimento da arquitetura de qualidade feita em São Paulo, são hoje invisíveis. Apenas quem as conhece são os arquitetos e interessados pela história da arquitetura, que têm acesso às publicações em que essas obras estão inseridas. Foram subtraídas ao ambiente urbano.

\section{A PRESERVAÇÃO DE PRÉDIOS DE APARTAMENTOS}

A preservação de prédios de apartamentos de valor elevado normalmente não apresenta problemas maiores, pois é mais viável levantar recurso para a sua manutenção e a transmissão de uma propriedade em condomínio por herança ou venda e compra não abre margem para alterações tão radicais no imóvel como acontece com as residências unifamiliares. Mas é nos prédios de valor menor que apenas incentivos mais significativos podem levar a uma preservação adequada dos valores que conduziram ao seu reconhecimento como valor cultural. Dois exemplos localizados em Santa Cecília e em processo de tombamento pelo Conpresp (CONPRESP, 2011) pela Resolução n. 05/CONPRESP/2011, serão apontados como exemplos opostos de conservação: o Prédio Maria Tereza, à Alameda Barros, e o Edifício Porchat, situado na esquina da Rua Apa com a Avenida São João.

O Prédio Maria Tereza, projeto e construção do Escritório Técnico de Construções Civis Vitale, de 1943 (PINHEIRO, 1997), manteve-se no exterior e nas áreas comuns como foi construído. O Edifício Porchat, projeto de Rino Levi, de 1940-1942, no entanto, encontra-se bastante deteriorado (ANELLI, 2001). Algumas razões podem ser identificadas para essa diferença, como a subdivisão da propriedade do imóvel, de um único proprietário para um condomínio, deterioração do ambiente urbano por alterações físicas nas vias 
FIGURA 15

Prédio Maria Tereza,

à Alameda Barros,

São Paulo. Publicado

em Acrópole 67

novembro 1943

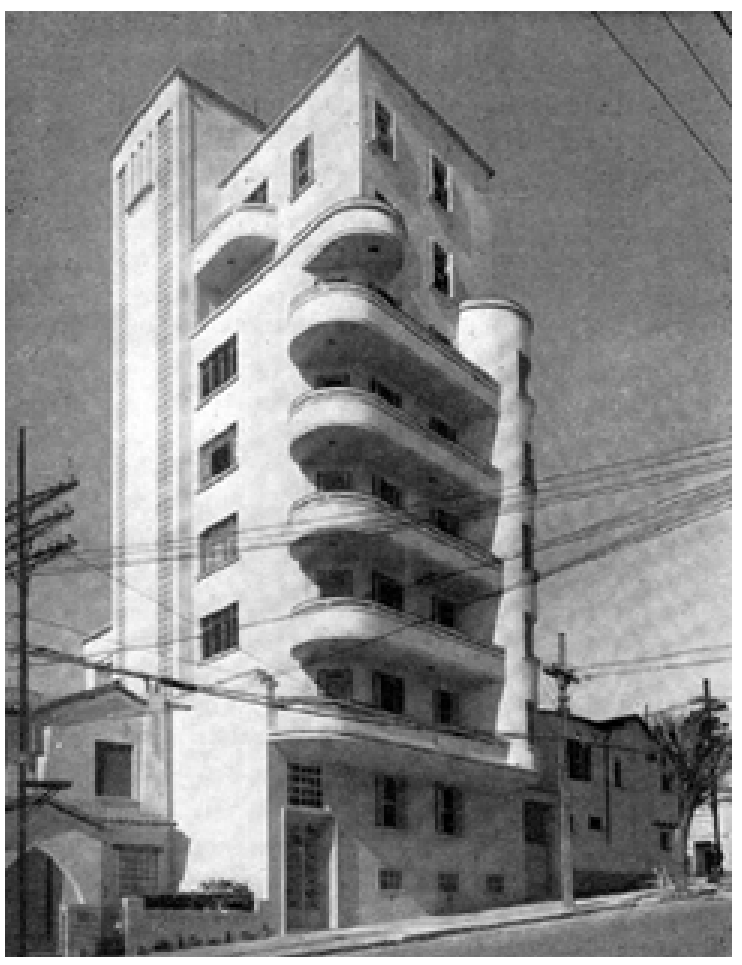

FIGURA 16

Prédio Maria Tereza.

Foto do autor. Junho

2006.

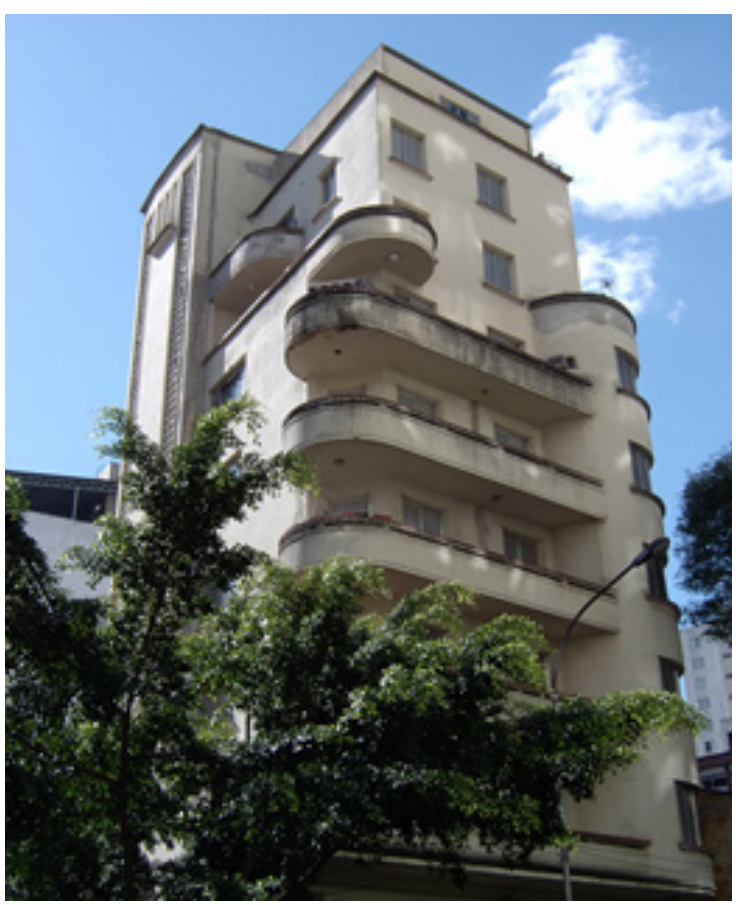

Rev. CPC, São Paulo, n.22 especial, p.233-254, abr. 2017. 
públicas lindeiras, como é o caso da via elevada construída nos anos 1970 na Avenida São João. Essas mudanças conduziram a uma perda de controle sobre intervenções descaracterizadoras feitas por proprietários dos apartamentos nas partes externas do edifício, como o fechamento de terraços com caixilhos dos mais diferentes tipos. No Prédio Maria Tereza essas intervenções não ocorreram, e o edifício manteve a sua integridade externa. $\mathrm{O}$ fechamento de terraços permite, sem dúvida, ampliar a área disponível interna e melhorar o isolamento acústico, mas às custas da perda da relação de cheios e vazios e de sombras e claros, que conferem caráter e beleza plástica ao edifício.

No caso do Edifício Porchat, como de muitos outros, a abertura de processo de tombamento ocorreu quando o edifício já se apresentava

FIGURA 17

Edifício Porchat,

Projeto de Rino Levi, 1940. (ANELLI,

2001) Foto:

P. C. Scheier

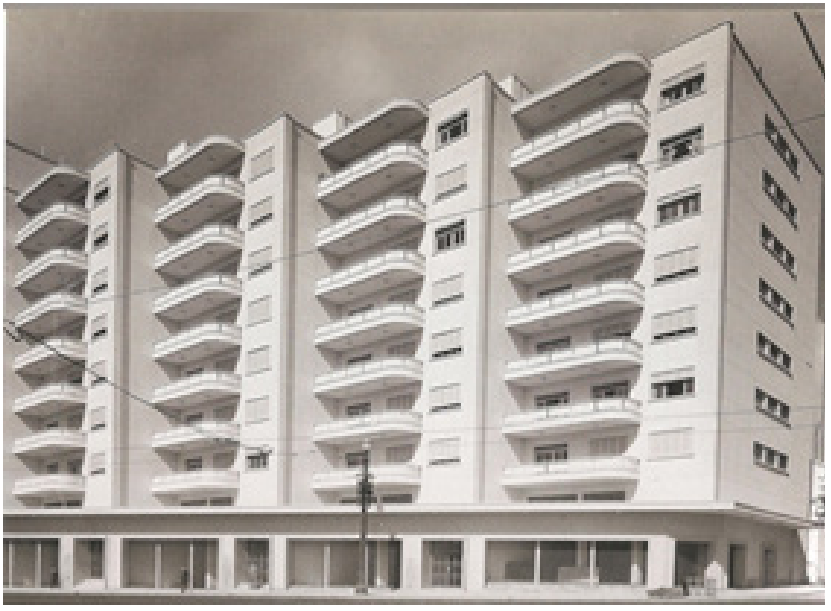

FIGURA 18

Edifício Porchat. Foto do autor abril 2006.

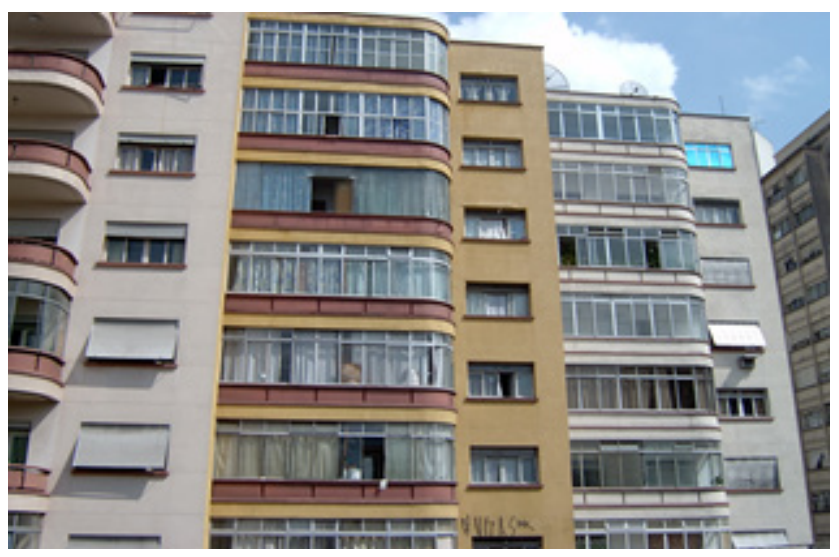


bastante alterado em relação à construção original. Não é objetivo das intervenções de restauro a necessária reversão de um bem ao seu suposto estado 'original', mas sim a identificação e valorização dos elementos que levaram esse bem a ser listado para tombamento como patrimônio cultural. Sem pretender apontar uma solução para as questões aqui levantadas, pode-se observar, na foto da Figura 18, que há caixilhos mais interferentes do que outros, bem como que a cor das pinturas executadas representa uma alteração visual significativa naquela arquitetura. Mas, fica claro que medidas corretivas e amenizadoras das interferências existentes só poderão ser alcançadas com a participação efetiva de proprietários e moradores, o que novamente remete à necessidade de abordagem com medidas de promoção da preservação, e não exclusivamente com medidas impositivas.

\section{REFERÊNCIAS}

ACAYABA, Marlene Millan. Residências em São Paulo 1947-1975. São Paulo: Projeto, 1986.

ANELLI, Renato; GUERRA, Abílio, KON, Nelson. Rino Levi: arquitetura e cidade. São Paulo: Romano Guerra, 2001.

CALDATTO BARBOSA, Gino. Chalé de madeira: a moradia popular de Santos. Dissertação de mestrado (Arquitetura e Urbanismo) - Faculdade de Arquitetura e Urbanismo da Universidade de São Paulo, São Paulo, 1998.

CAMPOS, Vitor J.B. Os chalés de madeira da cidade de Santos: um estudo programático e tipológico. Trabalho realizado para disciplina do Curso de Pós-graduação da FAU-USP. São Paulo, 1990

CONSELHO DE DEFESA DO PATRIMÔNIO HISTÓRICO ARQUEOLÓGICO, ARTÍSTICO E TURÍSTICO - CONDEPHAAT. Pedido e estudo de tombamento dos Chalés de Madeira de Santos. Dossiês Preliminares n. 00751/200o e n. 0119o/2015. Processo n. 73.630/2014.

CONSELHO MUNICIPAL DE PRESERVAÇÃO DO PATRIMÔNIO HISTÓRICO, CULTURAL E AMBIENTAL DA CIDADE DE SÃO PAULO - CONPRESP. Abertura de Processo de Tombamento da Residência Hans Broos. Processo n. 2008-0.372.043-9.

CONSELHO MUNICIPAL DE PRESERVAÇÃO DO PATRIMÔNIO HISTÓRICO, CULTURAL E AMBIENTAL DA CIDADE DE SÃO PAULO - CONPRESP. Abertura de Processo de Tombamento de 18 edifícios pioneiros, art déco e modernos. Processo $\mathrm{n}$. 2011-0.039.447-4.

DAUFENBACH, Karine. Reflexões sobre a obra de Hans Broos. Arquitextos, São Paulo, ano 11, n. 123.07, ago. 2010. Disponível em: <http://www.vitruvius.com.br/revistas/read/ arquitextos/11.123/3530>.

LEMOS, Carlos Alberto Cerqueira. Cozinhas, etc. São Paulo: Perspectiva, 1976. 
LEVI, Rino. Milano: Edizione di Comunitá, 1974

MINDLIN, Henrique. Modern architecture in Brazil. Rio de Janeiro: Colibris, 1956.

PINHEIRO, Maria Lucia Bressan. Modernizada ou moderna?: Arquitetura em São Paulo 19381945. Tese de doutorado (História da Arquitetura) - FAU-USP, 1997.

REIS FILHO, Nestor Goulart. Quadro da arquitetura no Brasil. São Paulo: Perspectiva, 1970.

SILVA, Rodolfo Ferreira da. Chalés de madeira no Morro São Bento: cartilha de conservação e restauro. Trabalho de Conclusão de Curso. Curso de Arquitetura da Universidade Santa Cecília. Santos, 2008. 